\title{
Brief 30: Probst an Grete Hermann (4.8.1936)
}

Sehr geehrtes Fräulein Dr. Hermann!

Heute früh besuchte uns hier Fräulein Trude Czepka aus Brünn (Hohlweg 52). Sie kam im Auftrage von Herrn Professor Dr. Adolf Plachý (Universität Brünn, Rechtsfakultät) und wollte Ihnen eine Bestellung ausrichten.

Herr Professor Plachý läßt Ihnen sagen, daß er Ihre „Quantenmechanik“ gelesen hat und daß er die Absicht hat, dazu zu schreiben. Es wird allerdings noch einige Zeit dauern, da er gegenwärtig mit anderen Arbeiten belastet sei. Er möchte mit Ihnen auch gern in Verbindung treten. Wir haben versprochen, die Post von Herrn Professor Plachý an Sie weiterzuleiten, um Verzögerungen nach Möglichkeit auszuschließen.

Wir teilen Ihnen das mit, damit Sie gegebenenfalls von sich aus die Verbindung mit Herrn Professor Plachý aufnehmen können.

Im Gespräch mit Fräulein Czepka wurde noch erwähnt, daß Herr Professor Plachý auch noch andere Arbeiten der Fries'schen Schule gelesen habe, und zwar in einer von einem Herrn aus Bratislava (etwa Dr. Ziegler?) besorgten Uebersetzung. Doch waren diese Angaben reichlich unklar.

Mit besten Grüßen

Verlag „Öffentliches Leben“

Inh.: Erich Irmer

i.v. Probst

(C) Springer Fachmedien Wiesbaden GmbH, ein Teil von Springer Nature 2019

K. Herrmann (Hrsg.), Grete Henry-Hermann: Philosophie - Mathematik -

Quantenmechanik, Frauen in Philosophie und Wissenschaft. Women

Philosophers and Scientists, https://doi.org/10.1007/978-3-658-16241-2_52 